\title{
Compliance and Barriers Facing Nurses with Surgical Site Infection Prevention Guidelines
}

\author{
Magda M. Mohsen1, Neima Ali Riad², Amina Ibrahim Badawy²*(i) \\ ${ }^{1}$ Community Health Nursing, Faculty of Nursing, Menoufia University, Al Minufya, Egypt \\ ${ }^{2}$ Medical Surgical Nursing, Faculty of Nursing, Menoufia University, Al Minufya, Egypt \\ Email: *amina73737373@yahoo.com
}

How to cite this paper: Mohsen, M.M., Riad, N.A. and Badawy, A.I. (2020) Compliance and Barriers Facing Nurses with Surgical Site Infection Prevention Guidelines. Open Journal of Nursing, 10, 15-33. https://doi.org/10.4236/ojn.2020.101002

Received: December 12, 2019

Accepted: January 10, 2020

Published: January 13, 2020

Copyright (c) 2020 by author(s) and Scientific Research Publishing Inc. This work is licensed under the Creative Commons Attribution International License (CC BY 4.0).

http://creativecommons.org/licenses/by/4.0/

(c) (i) Open Access

\begin{abstract}
Background: Surgical Site Infection (SSI) is defined as infection that occurring within 30 days after surgical procedure or within a year of implantation of prosthesis. Surgical Site Infection can happen in up to 30\% of surgical procedures and records for up to $14 \%$ of Hospital Acquired Infection (HAIs). Aim of the Study: The aim of this study was to assess levels of nurse's Compliance; knowledge and practice regarding prevention of surgical site infection Guidelines and identify the barriers facing nurses' compliance with surgical site infection prevention Guidelines. Design: Cross sectional descriptive study design self-reported survey. Settings: Data was collected from surgical departments from selected Menoufia Governorate Hospitals, Egypt. Sample: A large convenience sample of 450 nurses was selected. Initially 600 questionnaires were distributed, of which only 400 returned completed, a response rate of $66.6 \%$. Tools: was comprised of the: 1) Pre-designed structured questionnaire to assess nurses' socio-demographic characteristics' and Nurses' knowledge, 2) Likert-scale: to assess nurses' compliance, nurses' practice and nurses' barriers facing nurses with surgical site infection prevention guidelines. Study period: The study was conducted from July to November 2019 in the selected hospitals. Results: nurses' compliance mean scores were in low level with a mean of 13.01, it is clear that most of the nurses have poor knowledge, most of the nurses have poor practice about surgical site infection, concerning the most barriers of compliance facing nurses with surgical site infection prevention guidelines, were lack of a professional model, having no enough time, and some measures for the prevention of surgical site infection are not nurses' responsibilities. Conclusions: Nurses working in the surgical related wards reported a low level of knowledge, practice and compliance regarding the prevention of surgical site infection guidelines. The most barriers of compliance with surgical site infection prevention guidelines that reported by nurses were, lack of a professional model, nurses do not have enough time,
\end{abstract}


and some measures for the prevention of surgical site infection are not nurses' responsibilities. Recommendations: Evaluation of nurses' and hospitals' application of the guidelines is important to improve the quality of care. Education and training program should be conducted to improve nurses' knowledge and practice in some areas using evidence-based practice.

\section{Keywords}

Surgical Site Infection, Compliance, Knowledge and Practice

\section{Introduction}

Surgical site infections (SSIs) are the most preventable hospital acquired infection (HAI) related with any surgery [1] [2]. SSI is defined as infection that occurs within 30 days after a surgical procedure or within a year of implantation of a prosthesis. SSI can happen in up to $30 \%$ of surgical procedures and records for up to $14 \%$ of HAIs [3]. It was reported a huge weight in terms of patient morbidity and mortality and costs to healthcare around the world due to Surgical site infections (SSIs) [4]. The fundamental danger of contamination is microorganisms (viral or bacterial) entering surgical incisions. The development of SSIs depends upon on virulence, bacterial load, and the patient's ability to withstand infections [5]. Transmission of microorganisms can be minimized through following evidence based guidelines for prevention of transmission of them, including the aseptic technique. Hand washing techniques in pre-operative aseptic strategies consist of a number of factors such as preliminary hand washing, method of rubbing, drying of hands, wearing an operating gown, and wearing sterile gloves. One of the factors that affect the success of hand washing is the degree of compliance with the recommended standard procedures [6] [7].

Prevalence study found that wound contaminations after surgery represent SSIs happen in $2 \%$ - $5 \%$ of patients experiencing surgical procedure extending from 160,000 to 300,000 cases for each year in the US, [8] [9]. SSIs are related with delayed term of hospitalization, readmissions, re-intercessions, changeless incapacity or even passing [10].

Throughout the literature, SSIs were associated with factors including advanced age, malnutrition, metabolic diseases, smoking, obesity, hypoxia, and immune-suppression. Moreover, factors like application of skin antiseptics, preoperative shaving, antibiotic prophylaxis, preoperative skin preparation, inadequate sterilization of instruments, surgical drains, surgical hand scrubs, and dressing techniques were among the most frequently reported risk factors [11] [12]. The most critical issue in preventing surgical site infections is the entire and absolute compliance of health professionals with the recommendations in the guidelines [13] [14].

Although the occurrence of surgical site infections (SSIs) is a great deal higher in low- and middle-income nations in contrast to high-income countries, SSIs 
are nevertheless a common motive of infection in high-income international locations [15]. Clearly, better SSIs prevention is needed. Preventing SSI requires a multifactorial strategy as the increasing improvement of antibiotic resistance makes it essential that the operating room (OR) is free from infection as possible [16].

Wound contamination can be prevented by implementing certain guidelines from the nurses and other health care workers that minimize the risk of SSIs. Actions such as all staff complying with Preventing SSI guidelines including hygienic practices and correct cleaning of the OR between operations are examples of measures that can reduce SSI load in all health care facilities [17].

There is a general agreement that up to $60 \%$ of SSI would be reduced by applying sufficient counteractive action and checking nurses compliance with SSI [15] [17], since sets of measures (or "packages") have exhibited a decrease in SSI rates [18] [19].

As most SSIs are avoidable [20], all details preoperative, intraoperative and post-operative care should be investigated and evaluated to make certain highquality practices are evidence-based. Prevention of SSI is a balance between harm, cost, and patient value [15]. Surgical patients, who meet many fitness care specialists on their perioperative period, rely on OR nurse to provide advantageous care as properly as to make sure the prevention of SSIs. That is, OR nurses are accountable for enforcing hygiene and aseptic principles in the OR to stop and limit the spread of infections. In addition, OR nurses are responsible for perioperative care together with different professionals in the crew [21].

Nurses play a major comprehensive role and span of continuum care in preventing surgical site infections. Therefore, they can modify SSI risk factors in their daily practice such as improper hand hygiene and skin preparation, in order to prevent SSI. [7] [8]. Many sets of guidelines in this area have been proposed in the past decade by the organizations working in the area of SSI prevention, such as the Center for Disease Control and Prevention (CDC) [22], WHO, [23], and the National Institute for Health and Clinical Excellence (NICE). [24]. However, adherence to the recommended best practices according to the guidelines for SSI prevention remains low among nurses [22] [24]. Multiple studies have reported that proper practices for the prevention of infection among nurses have been affected by some barriers, such as Lack of knowledge, resources and SSI preventive guidelines, lack of direct leadership involvement, lack of dedicated time for implementation of the improvement activities, lack of dedicated time for training and education, poor access to supplies in support of identified and agreed action, poor communication, lack of awareness of the need to address the problem, lack of data to support and track improvement efforts, non-attendance or non-compliance with educational activities, absence of local standard operating protocols (SOPs) or an implementation manual for SSI prevention [9] [24].

\subsection{Significance of the Study}

Surgical site infection (SSI) is a significant clinical problem that affects the qual- 
ity of health care outcomes globally, particularly in developing countries. This infection can have serious impacts including: prolonged hospital stay, reduced quality of life, increased mortality, additional cost for patients and their family, and rising health care cost. In Egypt, a little nursing research has been done to assess the level of nurses' compliance, knowledge and practice regarding surgical site infection prevention guidelines and investigating the correlation among them, as well as, identifying the barriers facing the nurses to comply with guidelines of SSI. All over the world, the use of SSI prevention guidelines is supported by scientific research. However, In Menoufia Governorate in Egypt, the extent to which nurses implement these guidelines in surgical departments is still unclear. Therefore, there is a standing need to provide all Menoufia hospitals with written guidelines for nurses, patients and other health care employees to gain knowledge and practice regarding surgical site infection prevention (SSIs). Moreover, it might generate attention and motivation for further researches into this area.

\subsection{Aim of the Study}

The aim of this study was to assess levels of Nurse's Compliance, knowledge and practice regarding prevention of surgical site infection Guidelines and to identify the Barriers facing nurses' compliance with surgical site infection prevention Guidelines.

\subsection{Research Questions}

1) What is the level of Nurses' knowledge regarding prevention of surgical site infection Guidelines?

2) What is the level of nurses' practice regarding prevention of surgical site infection Guidelines?

3) What is the level of nurses' compliance with surgical site infection prevention Guidelines?

4) What are the barriers facing nurses' compliance with surgical site infection prevention Guidelines?

\section{Methodology}

\subsection{Design}

A cross-sectional descriptive study, design self-reported survey was conducted.

\subsection{Setting}

Data was collected from surgical departments from selected Menoufia Governorate Hospitals: (Menoufia University Hospital, Shebin El-Koom Teaching Hospital, Quwesna Central Hospital, Berkt El-Saba Central Hospital, Ashmoon General Hospital) as they represent a capital of big town in Menoufia Governorate-Egypt. 


\subsection{Sample Size Estimation}

In this study, it is used the Raosoft sample size calculator [25]. in which, margin of error was $5 \%$ is a common choice, confidence level was $95 \%$, the population size, 20,000, the response distribution was $50 \%$, the recommended sample size was 377 which calculated electronically based on the Raosoft sample size calculator. A large convenience sample of 450 nurses was selected to compensate for the expected low response rate and uncompleted questionnaires. The participants were from Shebin El-Koom University Hospital (175 participants), Shebin El-Koom Teaching Hospital (130), Quwesna Central Hospital (45), Berkt El-Saba Central Hospital (30), Ashmoon General Hospital (20). Initially 600 questionnaires were distributed, of which only 400 returned completed, a response rate of $66.6 \%$. Respondents were different genders, age, and years of experience.

Surgical site infection (SSI) is a significant clinical problem that affects the quality of health care outcomes globally, particularly in developing countries. This infection can have serious impacts including: prolonged hospital stay, reduced quality of life, increased

\subsubsection{Inclusion Criteria}

Staff nurses;

Nurses who will voluntarily participate and give consent.

\subsubsection{Exclusion Criteria}

Head nurses;

Student nurses;

Nurses who will refuse to participate in the study.

\subsection{Tools for Data Collection}

1) Pre-designed structured questionnaire was designed by the researchers in Arabic language after reviewing of the related literature. This tool was comprised of the following sections:

a) Section 1: Nurses' socio-demographic characteristic as regards their age, gender, educational level, working experience and attended surgical site infection prevention guidelines training programme previously.

b) Section 2: Nurses' knowledge: to evaluate the nurse's knowledge regarding application of surgical site infection prevention guidelines [26]. This part also was designed by the researchers based on literature review, which contained another 22 multiple choice questions,

Scoring System: the correct answer was given a score of one and the incorrect a score of zero. The total score of knowledge ranged between $0-22$. Levels of knowledge as the following: Low $=0$ to 7.3 , Moderate $=7.4$ to 14.6 , and High $=$ 14.7 to 22 .

2) Likert-scale: It consisted of:

a) Part 1: Likert-scale to assess nurse's compliance with surgical site infection prevention guidelines. It was designed by the researchers on the basis of the 
published and updated guidelines on prevention of surgical site infection from the WHO Surgical Site Infection Prevention Guidelines, (2016) [26]. This tool consisted of 9 items, of Likert-scale scores (never $=1$, sometimes $=2$, and always $=3$ ) to measure nurses' compliance with the guidelines. Scoring System: The score of nurses' compliance ranged from 9 - 27, levels of nurses' compliance as the following: Low $=9$ to 15 , Moderate $=$ more than 15 to 21 , and High $=$ more than 21 to 27 .

b) Part 2: Likert scale to assess Nurses practice: regarding surgical site infection prevention guidelines. This part was adopted from Sickder et al., (2014) [27] contained another 10 questions in which responses were answered in a 3-point Likert scale (never practiced, sometimes practiced, and always practiced). Responses range from 1 to 3 . The higher scores will indicate higher level of practice, Levels of practices: Low $=10-16.6$, Moderate $=16.7-23.3$ and High $=23.4-30$.

c) Part 3: Likert Scale to assess Nurses' Barriers facing nurse's compliance with surgical site infection prevention guidelines. It consisted of 11 items [26]. Questions in which responses were answered on a 3-point Likert scale (Disagree, Undecided and Agree).

\subsection{Procedure for Data Collection}

\subsubsection{Study Period}

The study was conducted between July to November 2019 in the selected hospitals.

\subsubsection{Approval to Conduct the Study}

An official letter was issued to the directors of Menoufia Governorates Hospitals, Egypt.

\subsubsection{Protection of Human Rights}

Each subject was informed about the purpose and the nature of the study. The subjects were informed that their participation is totally voluntary and the confidentiality and anonymity were assured.

\subsubsection{Ethical Considerations}

This study was approved by the Ethical Committee for scientific research review in Faculty of Nursing of Menoufia University. Ethical considerations were performed in accordance with the Declaration of Helsinki (World Medical Association, 2013). All participants received written and oral information about the study. Before the interviews took place, the participants signed a written consent and were ensured confidentiality. The heads of the departments in all the surgical departments were informed about the study and agreed to let their nurses be interviewed during work hours at work or another place of the nurses' choosing.

\subsubsection{Validity and Reliability}

Compliance, knowledge, practice, and barriers items showed an acceptable 
Cronbach $\alpha, 0.75,0.80,0.73$, and 0.75 respectively.

\subsubsection{Pilot Study}

The tools were administered to 50 nurses in a pilot study, the panel of experts approved all the sections of the tools, as well as the scoring systems to evaluate its applicability. Minor rewording for some items was made to improve readability and understandability for practice section, as it was adopted.

The questionnaire was distributed to the nurses working in the surgical department in the previously mentioned hospitals for filling it.

The questionnaires were completed by nurses in their surgical departments

\section{Statistical Analysis}

Data were analyzed using SPSS [28] version 21. The sum of scores for the items in the compliance, knowledge, and practice, parts were calculated. Frequencies of responses were determined. Differences between nurses' compliance were measured using the independent sample $\mathrm{T}$ test and analysis of variance test. The F-test of association was conducted to analyze the frequencies of nurses' responses.

\section{Results}

From 600 questionnaires were distributed, only 400 returned completed, a response rate of $66.6 \%$. The participants were from Shebin El-Koom University Hospital (175 participants), Shebin El-Koom Teaching Hospital (130), Quwesna Central Hospital (45), Berkt El-Saba Central Hospital (30), Ashmoon General Hospital (20). Respondents were different genders, age, and years of experience.

Table 1 shows that about two thirds of the studied sample were females $(65.8 \%)$, more than one third (39.0\%) of the sample were in the age group of 20 30 years and more than half (56.0\%) were having bachelor degree in nursing. Regarding Work experience in surgical ward, it is indicated that, (44.8\%) were having $1-5$ years experience in surgical ward. As well as, it indicates that $(81.5 \%)$ of nurses did not attend surgical site infection prevention guidelines training programme previously.

Table 2 describes frequency of nurse's responses concerning compliance of surgical site infection prevention guidelines. It is evident that, among 400 nurses, limited compliance with the surgical site infection prevention guidelines was obvious in several topics. Three quarters $(75.0 \%)$ of the nurses reported that they never ensure patients bathe or shower and (77.3\%) never limit the number of people and doors being opened, and (69.0\%) never check wounds for infection and use standard dressings on primary wounds.

Table 3 indicated that, nurses' compliance mean scores were in low level with a mean of $13.01(\mathrm{SD}= \pm 3.00)$, and majority $(84.75 \%)$ of the nurses were classified in low compliance, $(13.25 \%)$ in moderate compliance, and (2\%) in high compliance.

Table 4 describes frequency of Incorrect and Correct Knowledge regarding 
Table 1. Distribution of demographic characteristics of the studied sample $(\mathrm{N}=400)$.

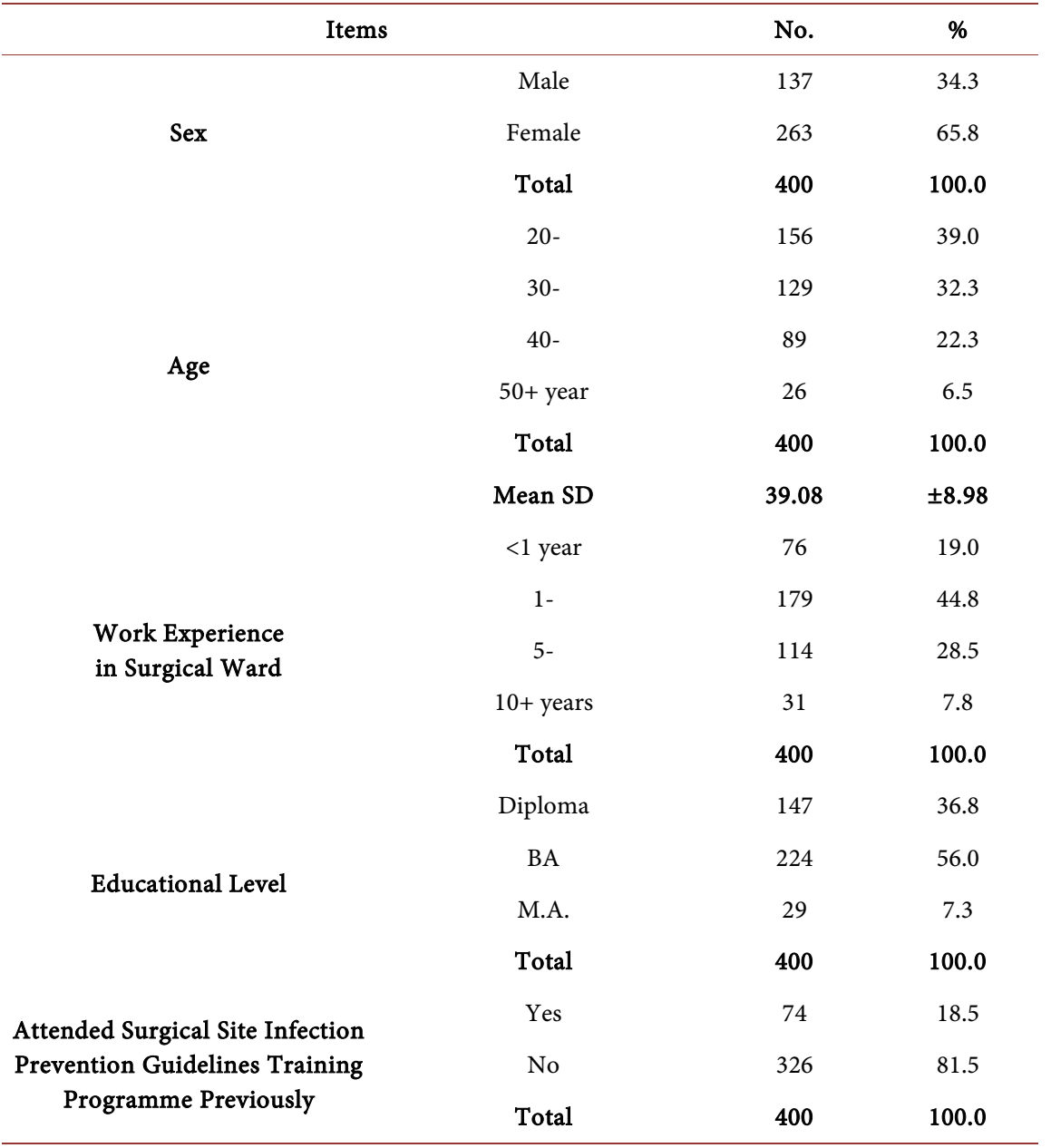

Table 2. Nurses compliance with surgical site infection prevention guidelines.

\begin{tabular}{|c|c|c|c|c|c|c|}
\hline \multirow{2}{*}{$\begin{array}{l}\text { Nurses Compliance with Surgical Site Infection } \\
\text { Prevention Guidelines }\end{array}$} & \multicolumn{2}{|c|}{ Never } & \multicolumn{2}{|c|}{ Sometimes } & \multicolumn{2}{|c|}{ Always } \\
\hline & No. & $\%$ & No. & $\%$ & No. & $\%$ \\
\hline \multicolumn{7}{|c|}{ A. Before Surgery } \\
\hline 1) Ensure patients bath or shower & 300 & 75.0 & 59 & 14.8 & 41 & 10.3 \\
\hline 2) Do not shave patients & 274 & 68.5 & 54 & 13.5 & 72 & 18.0 \\
\hline 3) Only use antibiotics when recommended & 255 & 63.8 & 67 & 16.8 & 78 & 19.5 \\
\hline $\begin{array}{l}\text { 4) Use chlorexidine alcohol) based antiseptic solutions } \\
\text { to prepare skin }\end{array}$ & 169 & 42.3 & 212 & 53.0 & 19 & 4.8 \\
\hline $\begin{array}{l}\text { 5) Surgical hand preparation should be performed by } \\
\text { scrubbing with either a suitable antimicrobial soap or } \\
\text { water or using a suitable alcohol) based hand rub before } \\
\text { donning sterile gloves }\end{array}$ & 277 & 69.3 & 83 & 20.8 & 40 & 10.0 \\
\hline \multicolumn{7}{|c|}{ B. During Surgery } \\
\hline 6) Limit the number of people and doors being opened & 309 & 77.3 & 50 & 12.5 & 41 & 10.3 \\
\hline $\begin{array}{l}\text { 7) Ensure all surgical equipment is sterile and maintain } \\
\text { asepsis throughout surgery }\end{array}$ & 297 & 74.3 & 84 & 21.0 & 19 & 4.8 \\
\hline
\end{tabular}


Continued

\section{After Surgery}

8) Do not continue antibiotics to prevent infection $\quad \begin{array}{llllll}258 & 64.5 & 82 & 20.5 & 60 & 15.0\end{array}$

9) Check wounds for infection and use standard dressings on primary wounds.

Table 3. Score of nurses compliance with surgical site infection prevention guidelines.

\begin{tabular}{cccc}
\hline $\begin{array}{c}\text { Score of Nurses Compliance with } \\
\text { Surgical Site Infection Prevention Guidelines }\end{array}$ & No. & $\%$ & f-p-Value \\
\hline Low Compliance & 339 & 84.75 \\
Moderate Compliance & 53 & 13.25 & $363.90^{* * *}$ \\
High Compliance & 8 & 2.00 & $13.01 \pm 3.00$
\end{tabular}

Table 4. Knowledge regarding surgical site infection prevention guidelines for nurses.

\begin{tabular}{|c|c|c|c|c|}
\hline \multirow{2}{*}{$\begin{array}{l}\text { Knowledge regarding Surgical Site } \\
\text { Infection Prevention Guidelines for Nurses }\end{array}$} & \multicolumn{2}{|c|}{ Incorrect } & \multicolumn{2}{|c|}{ Correct } \\
\hline & No. & $\%$ & No. & $\%$ \\
\hline \multicolumn{5}{|l|}{ A. Preoperative Measures } \\
\hline 1) Preoperative timing for preoperative bathing & 280 & 70.0 & 120 & 30.0 \\
\hline 2) Optimal surgical antibiotic prophylaxis & 295 & 73.8 & 105 & 26.3 \\
\hline 3) Hair removal & 314 & 78.5 & 86 & 21.5 \\
\hline 4) Surgical site preparation & 308 & 77.0 & 92 & 23.0 \\
\hline 5) Surgical hand preparation & 335 & 83.8 & 65 & 16.3 \\
\hline \multicolumn{5}{|c|}{ B. Perioperative and/or Intraoperative Measures } \\
\hline 6) Enhanced nutritional support & 239 & 59.8 & 161 & 40.3 \\
\hline 7) Perioperative discontinuation of immunosuppressive agents & 287 & 71.8 & 113 & 28.3 \\
\hline 8) Perioperative oxygenation & 282 & 70.5 & 118 & 29.5 \\
\hline 9) Maintaining normal body temperature (normothermia) & 266 & 66.5 & 134 & 33.5 \\
\hline $\begin{array}{l}\text { 10) Use of protocols for intensive perioperative blood glucose } \\
\text { control }\end{array}$ & 299 & 74.8 & 101 & 25.3 \\
\hline $\begin{array}{l}\text { 11) Maintenance of adequate circulating volume } \\
\text { control/normovolemia }\end{array}$ & 322 & 80.5 & 78 & 19.5 \\
\hline 12) Drapes and gowns & 345 & 86.3 & 55 & 13.8 \\
\hline 13) Wound protector devices & 306 & 76.5 & 94 & 23.5 \\
\hline 14) Incisional wound irrigation & 285 & 71.3 & 115 & 28.8 \\
\hline 15) Prophylactic negative pressure wound therapy & 258 & 64.5 & 142 & 35.5 \\
\hline 16) Use of surgical gloves & 264 & 66.0 & 136 & 34.0 \\
\hline 17) Changing of surgical instruments & 265 & 66.3 & 135 & 33.8 \\
\hline 18) Antimicrobial) coated sutures & 268 & 67.0 & 132 & 33.0 \\
\hline $\begin{array}{l}\text { 19) Laminar airflow ventilation systems in the context of } \\
\text { operating room ventilation }\end{array}$ & 286 & 71.5 & 114 & 28.5 \\
\hline
\end{tabular}


C. Postoperative Measures

\begin{tabular}{lllll} 
20) Surgical antibiotic prophylaxis prolongation & 313 & 78.3 & 87 & 21.8 \\
$\begin{array}{l}\text { 21) Advanced dressings } \\
\begin{array}{l}\text { 22) Antibiotic prophylaxis in the presence of a drain and } \\
\text { optimal timing for wound drain removal }\end{array}\end{array} 2^{298}$ & 74.5 & 102 & 25.5 \\
\hline
\end{tabular}

surgical site infection prevention guidelines for Nurses: which shows the overall responses of the participants to knowledge questions indicate that the participants have little knowledge about the surgical site infection. Responses of the nurses to the five questions of pre-operative measures shows that majority of them responded incorrect, as well, minority of nurses answered correct for perioperative and/or intraoperative measures questions, moreover, concerning postoperative measures questions, it is clear that, only (21.8\%) of nurses answered correct for the question asking about the surgical antibiotic prophylaxis prolongation.

From Table 5, it is clear that most of the nurses have poor knowledge about surgical site infection, as about two thirds of nurses (65.5\%) were in the low level of knowledge with mean knowledge score of $(6.00 \pm 5.97)$.

It is obvious that minority of nurses always practiced the ten items of surgical site infection prevention guidelines in Table 6. As only (5.8\%) of nurses always practiced washing hands before and after changing wound dressing touching the surgical site, $(6.0 \%)$ of them always practiced advising their patients to take preoperative showering bathing with anti-microbial agent, (8.3\%) always use an aseptic technique during surgical wound dressing, and (9.0\%) always use sterilized dressing material for cleaning surgical wound dressing.

Table 7 shows the levels and the mean total score of Nurses practice with surgical site infection prevention guidelines. It is clear from this table that, most of the nurses have poor practice about surgical site infection, as about three quarters of nurses $(74.5 \%)$ were in the low level of practice with mean practice score of $(14.71 \pm 4.65)$.

In Table 8, concerning Barriers of Compliance with surgical site infection prevention guidelines, about two thirds (59.0\%) of nurses agree that, lack of a professional model, nurses do not have enough time (64.0\%), and some measures for the prevention of surgical site infection are not nurses' responsibilities $(60.0 \%)$, are the most barriers facing them with surgical site infection prevention guidelines.

Table 9 illustrates the correlation among Age, experience, compliance, Knowledge, and practice. It is shown from this table that there was a strong statistical significant correlation among Age, experience, compliance, Knowledge, and practice for nurses in relation to surgical site infection prevention guidelines.

Table 10 revealed that, there was no statistical difference among nurses who attended surgical site infection prevention guidelines training programme previously and who did not. 
Table 5. Total score of nurses knowledge with surgical site infection prevention guideline.

\begin{tabular}{cccc}
\hline $\begin{array}{c}\text { Score of Nurses Knowledge with Surgical } \\
\text { Site Infection Prevention Guidelines }\end{array}$ & No. & $\%$ & F-p-Value \\
\hline Low & 262 & 65.5 & \\
Moderate & 90 & 22.5 & $1377.68^{\star * *}$ \\
High & 48 & 12.0 & \\
Total (Mean \pm SD) & \multicolumn{2}{c}{$6.00 \pm 5.97$} & \\
\hline
\end{tabular}

Table 6. Nurses practice response regarding surgical site infection prevention guidelines.

\begin{tabular}{|c|c|c|c|c|c|c|}
\hline \multirow{2}{*}{$\begin{array}{l}\text { Nurses Practice Response regarding } \\
\text { Surgical Site Infection Prevention Guidelines }\end{array}$} & \multicolumn{2}{|c|}{ Never } & \multicolumn{2}{|c|}{ Sometimes } & \multicolumn{2}{|c|}{ Always } \\
\hline & No. & $\%$ & No. & $\%$ & No. & $\%$ \\
\hline $\begin{array}{l}\text { 1) I wash my hands before and after changing wound } \\
\text { dressing touching the surgical site }\end{array}$ & 138 & 34.5 & 239 & 59.8 & 23 & 5.8 \\
\hline 2) I wash my hand before wearing the surgical glove & 277 & 69.3 & 83 & 20.8 & 40 & 10.0 \\
\hline 3) I perform pre-operative shaving right before surgery & 272 & 68.0 & 84 & 21.0 & 44 & 11.0 \\
\hline $\begin{array}{l}\text { 4) I administer pre-operative prophylactic antibiotic within } \\
\text { one hour before surgery }\end{array}$ & 290 & 72.5 & 78 & 19.5 & 32 & 8.0 \\
\hline $\begin{array}{l}\text { 5) I advise my patient to take preoperative showering } \\
\text { bathing with anti-microbial agent }\end{array}$ & 265 & 66.3 & 111 & 27.8 & 24 & 6.0 \\
\hline $\begin{array}{l}\text { 6) I use sterilized dressing material for cleaning surgical } \\
\text { wound dressing }\end{array}$ & 255 & 63.8 & 109 & 27.3 & 36 & 9.0 \\
\hline 7) I use an aseptic technique during surgical wound dressing & 291 & 72.8 & 76 & 19.0 & 33 & 8.3 \\
\hline 8) I Asses and monitor surgical site condition & 251 & 62.8 & 110 & 27.5 & 39 & 9.8 \\
\hline 9) I separate infected dressing from non-infected dressing & 223 & 55.8 & 115 & 28.8 & 62 & 15.5 \\
\hline 10) I use face mask during cleaning surgical wound dressing & 233 & 58.3 & 118 & 29.5 & 49 & 12.3 \\
\hline
\end{tabular}

Table 7. Total score of nurses practice with surgical site infection prevention guidelines.

\begin{tabular}{cccc}
\hline Score of Nurses' Practice & No. & $\%$ & F-p-Value \\
\hline Low & 298 & 74.5 & \\
Moderate & 73 & 18.2 & $1005.63^{* * *}$ \\
High & 28 & 7.3 & \\
Total (Mean \pm SD) & & $14.71 \pm 4.65$ & \\
\hline
\end{tabular}

Table 8. Barriers of compliance with surgical site infection prevention guidelines.

\begin{tabular}{lrrrrrr}
\hline \multicolumn{1}{c}{$\begin{array}{l}\text { Barriers of Compliance with Surgical } \\
\text { Site Infection Prevention Guidelines }\end{array}$} & \multicolumn{2}{c}{ Disagree } & \multicolumn{2}{c}{ Undecided } & \multicolumn{2}{c}{ Agree } \\
\cline { 2 - 7 } & No. & $\%$ & No. & $\%$ & No. & $\%$ \\
\hline $\begin{array}{l}\text { 1) Inadequate supply of surgical consumables } \\
\text { (cap, mask, scrub, antiseptic solution) }\end{array}$ & 95 & 23.8 & 102 & 25.5 & 203 & 50.8 \\
$\begin{array}{l}\text { 2) Lack of supervision of hospital infection control } \\
\text { committee }\end{array}$ & 119 & 29.8 & 52 & 13.0 & 229 & 57.3 \\
\hline
\end{tabular}




\section{Continued}

\begin{tabular}{|c|c|c|c|c|c|c|}
\hline $\begin{array}{l}\text { 3) Inadequate knowledge about disinfection and } \\
\text { sterilizing techniques }\end{array}$ & 126 & 31.5 & 63 & 15.8 & 211 & 52.8 \\
\hline $\begin{array}{l}\text { 4) Lack of training about measures for the } \\
\text { prevention of surgical site infection in hospital }\end{array}$ & 120 & 30.0 & 61 & 15.3 & 219 & 54.8 \\
\hline $\begin{array}{l}\text { 5) Lack of providing Evidence) based } \\
\text { recommendations on measures for the prevention of } \\
\text { surgical site infection in hospital }\end{array}$ & 133 & 33.3 & 41 & 10.3 & 226 & 56.5 \\
\hline 6) Unsuitable nurse patient ratio & 97 & 24.3 & 83 & 20.8 & 220 & 55.0 \\
\hline 7) Lack of a professional model & 106 & 26.5 & 58 & 14.5 & 236 & 59.0 \\
\hline 8) Poor integration of research findings in practice & 113 & 28.3 & 68 & 17.0 & 219 & 54.8 \\
\hline 9) Nurses do not have enough time & 78 & 19.5 & 66 & 16.5 & 256 & 64.0 \\
\hline 10) Nurses lack required skills & 113 & 28.3 & 66 & 16.5 & 221 & 55.3 \\
\hline $\begin{array}{l}\text { 11) Some measures for the prevention of surgical } \\
\text { site infection are not nurses' responsibilities }\end{array}$ & 91 & 22.8 & 69 & 17.3 & 240 & 60.0 \\
\hline
\end{tabular}

Table 9. Correlation among age, experience, knowledge, practice, compliance.

\begin{tabular}{cccccc}
\hline Items & Age & Experience & Knowledge & Practice & Compliance \\
\hline Age & 1.00 & & & & \\
Experience & $0.828^{* *}$ & 1.00 & & & \\
Knowledge & $0.273^{*}$ & $0.333^{* *}$ & 1.00 & & \\
Practice & $0.367^{* *}$ & $0.262^{* *}$ & $0.384^{* *}$ & 1.00 & \\
Compliance & $0.313^{* *}$ & $0.342^{* *}$ & $0.094^{* *}$ & $0.006^{* *}$ & 1.00 \\
\hline
\end{tabular}

Table 10. Effect of attending surgical site infection prevention guidelines training programme previously on compliance score.

\begin{tabular}{cccc}
\hline Items & Mean & $\pm S D$ & t-p-Value \\
\hline Yes & 13.01 & 3.00 & 0.98 \\
No & 12.81 & 3.00 & ns \\
\hline
\end{tabular}

\section{Discussion}

Effective surgical site infection prevention requires redesigning systems to reduce barriers and to optimize prevention strategies and guidelines based on evidence-based processes of care; all nurses should comply with the surgical site infection prevention guidelines which are essential for lowering surgical site infection rate [29].

The current study explores the nurse's compliance, Knowledge, and practices of surgical site infection prevention guidelines at Menoufia Governorate. The current study findings revealed that, among 400 nurses, limited compliance with the surgical site infection prevention guidelines was obvious in several topics. Three quarters $(75.0 \%)$ of the nurses reported that they never ensure patients bathe or shower, and (77.3\%) never limit the number of people and doors being 
opened, and (69.0\%) never check wounds for infection and use standard dressings on primary wounds, moreover, nurses' compliance mean scores were in low level with a mean of 13.01 ( $\mathrm{SD}=3.00)$, and majority $(84.75 \%)$ of the nurses were classified in low compliance, $(13.25 \%)$ in moderate compliance, and (2\%) in high compliance. These findings are similar to other studies such as Aloush., et al., [30], Jahansefat et al., [31], and Narendranath et al., [32], who reported poor compliance among nurses. As well, Alhirish et al., [33] in Egypt, and Rizwan et al., [34] who reported a significant increase in nosocomial infection in Pakistan as a result of poor compliance with infection prevention guidelines.

On the other hand, our findings contradict those of several other studies. El-Saed et al., [35] reported a high compliance rate for nurses. Aysha et al., [36] found satisfactory compliance after implementation of a nursing care program, and Sherpa et al., [37] revealed higher compliance of nurses for the guidelines, including hand washing, and using sterile gloves.

In addition, the current study findings describe frequency of incorrect and correct knowledge regarding surgical site infection prevention guidelines for nurses and indicated that the participants have little knowledge about the surgical site infection. As the answers of the nurses to the five questions of pre-operative measures show that majority of them responded incorrect, as well, minority of nurses answered correct for perioperative and/or intraoperative measures questions, moreover, concerning postoperative measures questions, it is clear that, only (21.8\%) of nurses answered correct for the question asking about the surgical antibiotic prophylaxis prolongation.

As well, it is clear that most of the nurses have poor knowledge about surgical site infection, as about two thirds of nurses (65.5\%) were in the low level of knowledge with mean knowledge score of $(6.00+5.97)$.

These results were in accordance with Sadaf., Shafqat, Hussain, 2018, [38] who concluded that, nurses had poor knowledge concerning surgical infection and this study revealed that the nurses' information was poor regarding interference of surgical site infection. Responses of the nurses to knowing the simplest technique for pre-operative shaving indicated that the majority (50) were response to affirmative that show that they understand it and thirty four nurses were response to NO that was a negative response.

Other study conducted by Zucco, Lavano, Nobile, Papadopoli, Bianco (2019) [39], they reported that, only $53.8 \%$ knew that preoperative hair removal, if necessary, should take place shortly before surgery, and $28.9 \%$ of the sample did not know the right definition of "bundle". Over three quarters of participants stated that they always perform hand antisepsis before and after biological sample collection while $9.7 \%$ considered that wearing gloves during this practice is sufficient to prevent SSI. Furthermore, 91\% of nurses reported that they always performed hand antisepsis before and after invasive procedures. Their study findings highlight the areas that were most lacking in nurses' training and for which targeted activities are needed. These data could support healthcare managers to implement interventions focused at enabling adherence to effective pre- 
vention practices to reduce risk to all patients.

Moreover, other study reported that when assessing knowledge on strategies for SSI prevention, more than two thirds (73\%) of the participants knew that the appropriate time for shower or bath with an antiseptic agent is the day before surgery, but only $53.8 \%$ knew that preoperative hair removal, if necessary, should take place shortly before surgery. Moreover, $28.9 \%$ of the sample did not know the right definition of "bundle". When nurses were asked to rate the effectiveness of some interventions for SSI prevention, dressing change if it is visibly soiled received the highest score (8.9) [39].

In addition, it is obvious that minority of nurses always practiced the ten items of surgical site infection prevention guidelines. As only (5.8\%) of nurses always practiced washing hands before and after changing wound dressing touching the surgical site, $(6.0 \%)$ of them always practiced advising their patients to take preoperative showering bathing with anti-microbial agent, (8.3\%) always use an aseptic technique during surgical wound dressing, and (9.0\%) always use sterilized dressing material for cleaning surgical wound dressing.

As well, most of the nurses have poor practice about surgical site infection, as about three quarters of nurses (74.5\%) were in the low level of practice with mean practice score of $(14.71+4.65)$.

These results were in accordance with Sadaf, Shafqat, Hussain, 2018 [38] who concluded that, the current study also revealed that the practice of the nurses regarding surgical site infection is not satisfactory. Most of the participants were agree $41(35.1 \%)$ to the question that they wash hands before and after changing wound dressing, 23 (13.5\%) were strongly agree, 30 (28.7\%) were disagree and only 7 (4.1\%) strongly disagreed which show that most of the participants have good practice regarding hand washing. Responses of the participants to another question that performing pre-operative shaving before surgery is necessary, in which 26 (26.9\%) was agreed.

Another study was in accordance with our study such as Zucco, Lavano, Nobile, Papadopoli, Bianco, (2019) [39] stated that, over three quarters (75.2\%) of participants stated that they always perform hand antisepsis before and after biological sample collection, while $9.7 \%$ considered that wearing gloves during this practice is sufficient to prevent SSIs. Furthermore, $91 \%$ of nurses reported to always perform hand antisepsis before and after invasive procedures (e.g. peripheral intravenous catheter insertion, urethral catheterization, etc.). A vast majority of respondents (93.2\%) "always/often" reported the utilization of single-use protective equipment in patients with an infectious disease. Only (14.1\%) of respondents reported the proper duration of antibiotic prophylaxis $(<24$ hours after surgery) in their unit (77\%) of the sample self-reported that a wound culture was performed in case of SSI signs and/or symptoms. When investigating the replacement of the wound dressing, only $55.1 \%$ of the sample reported the correct frequency for changing of the dressing, and $61.9 \%$ of nurses reported the utilization of adhesive drapes. 
Furthermore, concerning barriers of compliance with surgical site infection prevention guidelines, about two thirds of nurses agree that, lack of a professional model, nurses do not have enough time, and some measures for the prevention of surgical site infection are not nurses' responsibilities, are the most barriers facing them with surgical site infection prevention guidelines. Aloush, et al., (2017) [30] their finding were in accordance with our study, as in their study, the Participants reported several barriers that prevented their compliance with the guidelines, especially lack of education, lack of a professional model, and poor integration of research findings in practice. They also stated that, $(63 \%)$ of the participants, had received no education about the guidelines in their schools. This finding supports the significance of education in the improvement of nurses' compliance, as reported in other studies [40] [41].

In relation to the correlation among age, experience, compliance, Knowledge, and practice, the current study indicated that there was strong statistical significant correlation among Age, experience, compliance, Knowledge, and practice for nurses in relation to surgical site infection prevention guidelines; indicating those older nurses who are more knowledgeable and practice, the more compliance with surgical site infection prevention guidelines. As well, our study indicated that, there was no statistical difference among nurses who attended surgical site infection prevention guidelines training programme previously and who did not.

These results were in accordance with Sadaf, Shafqat, Hussain, 2018 [38] who explained that, the link between Knowledge and practice is positive and association is critical. As well, Knowledge could be necessary that affects the performance. The study shows that nurses have poor Knowledge and practices concerning surgical infection this study reveals that the nurses' knowledge was poor regarding interference of surgical site infection. In a study that was in accordance with our study, previous education with VAP, more years of experience, and was important factors seeming to increase nurses' compliance. These findings highlighted the significance of education and training in the improvement of nurses' compliance and quality of care, and support the reports from previous studies [31] [42].

\section{Strengths and Limitations}

- A major strength is that the current study evaluated nurses' knowledge, practice, compliance and barriers of the guidelines of SSI.

- On the other hand, one limitation is the use of self-reported measures to evaluate nurses' knowledge, practice, and compliance.

\section{Conclusions}

- Nurses working in the surgical related wards reported a low level of knowledge, practice and compliance regarding the prevention of surgical site infection guidelines. 
- The most barriers of compliance with surgical site infection prevention guidelines that reported by nurses were: lack of a professional model, nurses do not have enough time, and some measures for the prevention of surgical site infection are not nurses' responsibilities.

- The current study indicated that there was strong statistical significant correlation among age, experience, compliance, knowledge, and practice for nurses in relation to surgical site infection prevention guidelines.

\section{Recommendations}

- Evaluation of nurses' and hospitals' application of the guidelines is important to improve the quality of care.

- Education and training program should be conducted to improve nurses' knowledge and practice in some areas using evidence-based practice.

- Improve compliance with the surgical site infection prevention guidelines through comprehensively modified and updated nursing curriculum to include the prevention of surgical site infection.

- Future studies are recommended to conduct observational measurement to enhance the reliability of the findings.

- The hospital administrators need to conduct education and training programs to enhance knowledge of SSI prevention to improve the quality of nursing care in this area.

\section{Conflicts of Interest}

The authors declare no conflicts of interest regarding the publication of this paper.

\section{References}

[1] Badia, J.M., Casey, A.L., Petrosillo, N., Hudson, P.M., Mitchell, S.A. and Crosby, C. (2017) Impact of Surgical Site Infection on Healthcare Costs and Patient Outcomes: A Systematic Review in Six European Countries. Journal of Hospital Infection, 96, 1-15. https://doi.org/10.1016/j.jhin.2017.03.004

[2] Frances, L., Brigid, M., Wendy, C., Yu, L., Karen, W., Nicola, M., Shirley, M., Frances, O. and Andrea, P. (2018) Preventing Surgical Site Infections: Facilitators and Barriers to Nurses' Adherence to Clinical Practice Guidelines-A Qualitative Study. Journal of Clinical Nursing, 28, 1643-1652.

https://doi.org/10.1111/jocn.14766

[3] Patil, V.B., Raval, R.M. and Chavan, G. (2018) Knowledge and Practices of Health Care Professionals to Prevent Surgical Site Infection in a Tertiary Health Care Centre. International Surgery Journal, 5, 2248-2251.

[4] Akhter, M.S., Verma, R. and Madhukar, K.P. (2016) Incidence of Surgical Site Infection in Post Operative Patients at a Tertiary Care Centre in India. Journal of Wound Care, 25, 210-2, 214-7. https://doi.org/10.12968/jowc.2016.25.4.210

[5] Mockford, K. and O'Grady, H. (2017) Prevention of Surgical Site Infections. Surgery, 35, 495-499. https://doi.org/10.1016/j.mpsur.2017.06.012

[6] Maria, Q., Jenny, L. and Sofia, A. (2019) Intraoperative Prevention of Surgical Site 
Infections as Experienced by Operating Room Nurses. International Journal of Qualitative Studies on Health and Well-Being, 14, Article ID: 1632109. https://doi.org/10.1080/17482631.2019.1632109

[7] Molina, G., Jiang, W., Edmondson, L., Gibbons, L., Huang, L.C., Kiang, M.V. and Singer, S.J. (2016) Implementation of the Surgical Safety Checklist in South Carolina Hospitals Is Associated with Improvement in Perceived Perioperative Safety. Journal of the American College of Surgeons, 222, 725-736. https://doi.org/10.1016/j.jamcollsurg.2015.12.052

[8] World Health Organization (2014) Healthcare-Associated Infections: Fact Sheet. http://www.who.int/gpsc/country_work/gpsc_ccisc_fact_sheet_en.pdf

[9] Magill, S., Hellinger, W., Cohen, J., Kay, R., Bailey, C., Boland, B., et al. (2012) Prevalence of Healthcare-Associated Infections in Acute Care Hospitals in Jacksonville, Florida. Infection Control \& Hospital Epidemiology, 33, 283-291. https://doi.org/10.1086/664048

[10] Berríos-Torres, S.I., Umscheid, C.A., Bratzler, D.W., Leas, B., Stone, E.C., Kelz, R.R., et al. (2017) Centers for Disease Control and Prevention Guideline for the Prevention of Surgical Site Infection. JAMA Surgery, 152, 784-791. https://doi.org/10.1001/jamasurg.2017.0904

[11] Health Research \& Educational Trust (2018) Surgical Site Infections Change Package: 2018 Update. Health Research \& Educational Trust, Chicago, IL.

[12] Gaines, S., Luo, J.N., Gilbert, J., Zaborina, O. and Alverdy, J.C. (2017) Optimum Operating Room Environment for the Prevention of Surgical Site Infections. Surgical Infections, 18, 503-507. https://doi.org/10.1089/sur.2017.020

[13] Ding, S., Lin, F., Marshall, A.P. and Gillespie, B.M. (2017) Nurses' Practice in Preventing Postoperative Wound Infections: An Observational Study. Journal of Wound Care, 26, 28-37. https://doi.org/10.12968/jowc.2017.26.1.28

[14] Qasem, M.N. and Hweidi, I.M. (2017) Jordanian Nurses' Knowledge of Preventing Surgical Site Infections in Acute Care Settings. Open Journal of Nursing, 7, 561-582. https://doi.org/10.4236/ojn.2017.75043

[15] Allegranzi, B., Bischoff, P., de Jonge, S., Kubilay, N.Z., Zayed, B., Gomes, S.M., et al. (2016) New WHO Recommendations on Preoperative Measures for Surgical Site Infection Prevention: An Evidence-Based Global Perspective. The Lancet Infectious Diseases, 16, e276-e287. https://doi.org/10.1016/S1473-3099(16)30398-X

[16] Adeyi, O.O., et al. (2017) Drug-Resistant Infections: A Threat to Our Economic Future. World Bank Group, Washington DC.

[17] Liu, Z., et al. (2018) Intraoperative Interventions for Preventing Surgical Site Infection: An Overview of Cochrane Reviews. Cochrane Database of Systematic Reviews, No. 2. https://doi.org/10.1002/14651858.CD012653.pub2

[18] Adriana, C. and Camila, S. (2017) Surgical Site Infection Prevention: An Analysis of Compliance with Good Practice in a Teaching. Journal of Infection Prevention, 18, 301-306. https://doi.org/10.1177/1757177417703190

[19] Senay, K. and Ayse, B. (2017) Nurses' Compliance with Isolation Precautions and the Affecting Factors. Applied Nursing Research, 38, 175-178. https://doi.org/10.1016/j.apnr.2017.10.014

[20] Mellin-Olsen, J., McDougall, R.J. and Cheng, D. (2017) WHO Guidelines to Prevent Surgical Site Infections. The Lancet Infectious Diseases, 17, 260-261. https://doi.org/10.1016/S1473-3099(17)30078-6

[21] Nordström, A. and Wihlborg, M. (2019) A Phenomenographic Study of Swedish 
Nurse Anasthetists' and OR Nurses' Work Experiences. AORN Journal, 109, 217-226. https://doi.org/10.1002/aorn.12582

[22] Berríos-Torres, S.I., Umscheid, C.A., Bratzler, D.W., Leas, B., Stone, E.C., Kelz, R.R., et al. (2017) Centers for Disease Control and Prevention Guideline for the Prevention of Surgical Site Infection, 2017. JAMA Surgery, 152, 784-791.

https://doi.org/10.1001/jamasurg.2017.0904

[23] World Health Organization (2019) Global Guidelines on the Prevention of Surgical Site Infection. http://apps.who.int/iris/bitstream/10665/250680/1/9789241549882-eng.pdf

[24] National Institute for Health and Clinical Excellence (NICE) (2019) Surgical Site Infection: Prevention and Treatment of Surgical Site Infection. NICE, London. http://www.nice.org.uk/nicemedia/pdf/CG74NICEGuideline.pdf

[25] Raosoft (2004) Raosoft Sample Size Calculator [Computer Program]. Raosoft, Inc., Seattle, WA.

[26] WHO Surgical Site Infection Prevention Guidelines (2016) Web Appendix 1. Overview of Available Relevant Guidelines on Surgical Site Infecion Prevention.

[27] Sickder, H.K., Sae-Sia, W. and Petpichetchian, W. (2014) Nurses' Knowledge and Practice Regarding Prevention of Surgical Site Infection in Bangladesh.

[28] IBM (2012) Statistical Package for the Social Sciences (SPSS) [Computer Program]. IBM, Armonk, NY.

[29] Wilson, J. (2016) Guidance on Preventing Surgical Site Infection. Nursing Times, 112, 13-15.

[30] Aloush, S., et al. (2017) Compliance of Nurses and Hospitals with Ventilator-Associated Pneumonia Prevention Guidelines A Middle Eastern Survey. Journal of Nursing Care Quality, 33, E8-E14.

[31] Jahansefat, L., Vardanjani, M.M., Bigdelian, H., Massoumi, G., Khalili, A. and Mardani, D. (2016) Exploration of Knowledge of, Adherence to, Attitude and Barriers toward Evidence Based Guidelines (EBGs) for Prevention of Ventilator Associated Pneumonia (VAP) in Healthcare Workers of Pediatric Cardiac Intensive Care Units (PCICUs): A Quali-Quantitative Survey. Health Science, 5, 67-73.

[32] Narendranath, V., Nandakumar, B. and Sarala, K. (2017) Epidemiology of Hospital-Acquired Infections in a Tertiary Care Teaching Hospital in India: A CrossSectional Study of 79401 Inpatients. International Journal of Community Medicine and Public Health, 4, 335-339. https://doi.org/10.18203/2394-6040.ijcmph20170063

[33] Alhirish, M.H., Asfour, H.I. and El-Soussi, A.H. (2016) Nurses' Compliance of Evidence-Based Guidelines for Preventing VAP in CCUs. Journal of High Institute of Public Health, 40, 475-496. https://doi.org/10.21608/jhiph.2010.20616

[34] Rizwan, M., Ikram, A., Zaman, G., Satti, L. and Ahmed, P. (2017) Surveillance of Device-Associated Infections in Intensive Care Units of a Tertiary Care Hospital. Journal of Hospital Infection, 95, 101-102. https://doi.org/10.1016/j.jhin.2016.10.012

[35] El-Saed, A., Al-Jardani, A., Althaqafi, A., et al. (2016) Ventilator Associated Pneumonia Rates in Critical Care Units in 3 Arabian Gulf Countries: A 6-Year Surveillance Study. American Journal of Infection Control, 44, 794-798. https://doi.org/10.1016/j.ajic.2016.01.042

[36] Aysha, Z.M.S., El-Din, S.M.A., Attia, N.R. and Ibrahim, M. (2016) Efficacy of Implementing Nursing Care Protocol on the Incidence of Ventilator Associated 
Pneumonia in Intensive Care Unit at Tanta Emergency Hospital. Journal of American Science, 12, 40-52.

[37] Sherpa, P.C., Chakrabarty, J. and D’Souza, P.J.J. (2016) Critical Care Provider's Practices for Prevention of Ventilator Associated Pneumonia. Indian Journal of Applied Research, 5.

[38] Sadaf, S., Shafqat, I. and Hussain, A. (2018) Nurse's Knowledge and Practice Regarding Prevention of Surgical Site Infection at Allied Hospital Faisalabad. International Journal of Scientific \& Engineering Research, 9, 351-369. http://www.ijser.org

[39] Zucco, R., Lavano, F., Nobile, C.G.A., Papadopoli, R. and Bianco, A. (2019) Adherence to Evidence-Based Recommendations for Surgical Site Infection Prevention: Results among Italian Surgical Ward Nurses. PLOS ONE, 14, e0222825.

https://doi.org/10.1371/journal.pone.0222825

[40] Akdogan, O., Ersoy, Y., Kuzucu, C., Gedik, E., Togal, T. and Yetkin, F. (2017) Assessment of the Effectiveness of a Ventilator Associated Pneumonia Prevention Bundle that Contains Endotracheal Tube with Subglottic Drainage and Cuff Pressure Monitorization. The Brazilian Journal of Infectious Diseases, 21, 276-281. https://doi.org/10.1016/j.bjid.2017.01.002

[41] Hassan, Z.M. and Wahsheh, M.A. (2017) Knowledge Level of Nurses in Jordan on Ventilator-Associated Pneumonia and Preventive Measures. Nursing in Critical Care, 22, 125-132. https://doi.org/10.1111/nicc.12273

[42] Jordan, A., Badovinac, A., Spalj, S., Par, M., Slaj, M. and Plancak, D. (2014) Factors Influencing Intensive Care Nurses' Knowledge and Attitudes Regarding Ventilator Associated Pneumonia and Oral Care Practice in Intubated Patients in Croatia. The American Journal of Infection Control, 42, 1115-1117. https://doi.org/10.1016/j.ajic.2014.07.008

\section{Abbreviations}

Surgical Site Infections (SSIs);

Hospital-Acquired Infection (HAI);

Operating Room (OR);

Control and Prevention (CDC);

World Health Organization (WHO);

National Institute for Health and Clinical Excellence (NICE). 